ISSN electrónico: 2172-9077

https://doi.org/10.14201/fjc201816171184

\title{
¿POR QUÉ SHOWMATCH? UN ACERCAMIENTO AL CONSUMO TELEVISIVO DE UNO DE LOS PROGRAMAS MÁS VISTOS EN ARGENTINA
}

\section{Why Showmatch? An Approach to Television Consumption of One of the Most Seen Programs in Argentina}

\author{
Dra. Yamila Heram \\ Investigadora del CONICET, Profesora de la Universidad de Buenos Aires, Argentina. \\ E-Mail: yaheram@yahoo.com.ar \\ (iD http://orcid.org/0000-0002-9209-4571
}

Fecha de recepción del artículo: 25/08/2017

Fecha de aceptación definitiva: 19/03/2018

\begin{abstract}
RESUMEN
Showmatch se mantiene, casi inalterado, en la pantalla desde hace más de una década. Es un producto faro de la televisión de aire argentina. Alrededor de él se organiza e ilumina el resto de la programación, se producen programas ad hoc y genera tema de agenda en los demás medios de comunicación. Nos interesa acerarnos al análisis de Showmatch a partir de un doble objetivo. En primer lugar, dar cuenta de las características del programa. En segundo lugar, indagar en las formas de consumos y los gustos de las audiencias que miran Showmatch. Los dos objetivos se articulan en la trama argumental sostenida por una hipótesis: los elementos constitutivos y permanentes del programa no conlleva necesariamente a ser motivo de elección por parte de las audiencias. El diseño metodológico de esta investigación articula la indagación empírica sobre los gustos y formas de consumo con la reflexión sobre la las características del programa.
\end{abstract}

Palabras clave: Showmatch; Televisión; Consumo; Audiencia; Recepción.

\begin{abstract}
Showmatch has remained, almost unchanged, on the screen for more than a decade. It is a beacon product of Argentine air television. Around it organizes and illuminates the rest of the programming, produces ad hoc programs and generates agenda item in the other media. We are interested in the analysis of Showmatch from a double objective. Firstly, realize the characteristics of the program. Secondly, inquire into the forms of consumption and the tastes of the audiences who watch Showmatch. The two objectives are articulated in the plot line supported by a hypothesis: the constitutive and permanent elements of the program do not necessarily lead to a choice by the audiences. The methodological design articulates the empirical inquiry on the tastes and forms of consumption with the reflection on the characteristics of the program.
\end{abstract}

Key words: Showmatch; Television; Consumption; Audience; Reception. 


\section{INTRODUCCIÓN}

Desde hace 11 años el inicio del programa Showmatch y su certamen de Bailando por un sueño ${ }^{1}$ suscita expectativa, promoción y atención por parte de los medios de comunicación. Es uno de los programas más vistos de la televisión de aire argentina, una gran cantidad de programas satélites se ocupan de instalar una agenda de temas en relación con el certamen y la grilla de televisión de los canales de aire se reorganiza en función del programa (Heram, Toledo, Merchert y Bleiz, 2017). La permanencia de Marcelo Tinelli como conductor se remonta a 1990 con el programa Ritmo de la noche y VideoMatch, desde ese entonces hasta la actualidad ha sido uno de los conductores televisivos que más han permanecido en la pantalla. Paradójicamente, desde el campo académico de la comunicación, Showmatch no ha sido tema de gran indagación teórico-analítica.

El objetivo de este artículo es doble. En primer lugar, dar cuenta de las características del programa. En segundo lugar, indagar en las formas de consumos y los gustos de las audiencias que miran Showmatch. Los dos objetivos se articulan en la trama argumental sostenida por una hipótesis: los elementos constitutivos y permanentes del programa no conlleva necesariamente a ser motivo de elección por parte de las audiencias. El trabajo, si bien se circunscribe en el análisis puntual de caso, se enmarca en la tradición argentina de los estudios sobre consumos culturales (Wortman, 2015; Grillo, Papalini y Benítez Largui, 2016; Jacks, 2011, Saintout y Ferrante, 2006, Varela y Grimson, 1999; Mata, 1997; García Canclini, 1995, Landi, Quevedo y Vacchieri, 1992; Terrero, 1997; 1999; entre otros).

El diseño metodológico de esta investigación articula la indagación empírica sobre los gustos y formas de consumo con la reflexión sobre la las características del programa. Las bases empíricas de este trabajo son de carácter exploratorio y descriptivo. Se trabajó a partir de una encuesta online sobre los gustos y formas de consumo, realizada en el mes de mayo de 2017. La muestra estuvo conformada por 305 casos validados, correspondiente a personas entre 15 y 70 años de edad que habitan en la Ciudad Autónoma de Buenos Aires y Gran Buenos Aires, Argentina. También se complementó el análisis con el visionado del programa y la medición de la inserción publicitaria.

El trabajo está organizado en diferentes apartados. En el primero compartimos algunas precisiones metodológicas. En el segundo, realizamos un recorrido sintético y panorámico sobre el programa. En el siguiente apartado presentamos un estudio de caso sobre las características preponderantes de los gustos de las audiencias y formas de consumo del programa. Finalmente, en las conclusiones compartimos los resultados más relevantes del análisis.

\section{Precisiones metodológicas}

Para cumplir los objetivos planteados, el diseño metodológico de la investigación articula la indagación empírica sobre los gustos y formas de consumo con la reflexión sobre las especificidades del programa. Trabajamos en una doble vía, por un lado, realizamos un visionado de Showmatch para identificar cuáles son los elementos constitutivos del programa, también nos basamos en trabajos previos que nos permiten caracterizarlo, así como entender su circulación dentro del entramado mayor que es la televisión de aire. Esta primera caracterización nos permite ponerlo en relación con las formas de consumo y gustos de las audiencias que es otro de los objetivos, articulando el análisis de caso con las reflexiones teóricas sobre la temática de consumos culturales.

Para llevar adelante el análisis de caso realizamos una encuesta estandarizada que es la base empírica de este trabajo que es carácter descriptivo y exploratorio. Se realizó un cuestionario online difundi-

\footnotetext{
${ }^{1}$ Vale aclarar que el nombre del programa es Showmatch y Bailando por un sueño es un segmento del mismo, aunque actualmente este ocupa la totalidad de la emisión. En adelante usaremos ambos nombres de manera indistinta.
} 
do por las diferentes redes sociales (Facebook y Twitter) de los integrantes del grupo de investigación en el que se enmarca este trabajo ${ }^{2}$. Es decir, la muestra de la encuesta es de carácter casual o incidental, para evitar entonces la sobrerrepresentación de personas vinculadas con las ciencias sociales se utilizaron diferentes estrategias, para así alcanzar un grupo lo más variado y heterogéneo posible, por ejemplo, se publicó la encuesta en grupos de Facebook sobre televisión, tomando elementos del método de la bola de nieve se pidió que se comparta el cuestionario llegando así a un universo más amplio y heterogéneo.

El universo de análisis estuvo conformado por personas entre 15 y 70 años que habitan en la Ciudad Autónoma de Buenos Aires y Gran Buenos Aires. La encuesta, de carácter causal o incidental, estuvo conformada por 305 casos validados. La encuesta circuló por las diversas redes sociales durante el mes de mayo de 2017. El corte temporal remite a caracterizar en un aquí y ahora delimitado, diferenciándose de los trabajos que estudian evolutivamente los cambios y continuidades en el consumo de determinado producto. La relevancia del análisis puntual de caso reside en el lugar hegemónico que tiene Showmatch en los medios de comunicación y en la vida cotidiana. Muchas veces, los propios medios legitiman y promocionan al programa apelando a que «a la gente lo mira». Consideramos que esta investigación, si bien es localizada y trabaja con una muestra acotada, es un insumo para cuestionar dichas afirmaciones y complejizar los motivos por los cuáles se lo mira.

El cuestionario se organizó a partir de dos ejes: formas de consumo y gustos. En primer lugar, se indagó -a partir de un sistema de preguntas cerradas con múltiples opciones de respuestas- sobre las formas de consumo del programa, luego se realizaron tres preguntas abiertas sobre los gustos. Dos de ellas direccionadas hacia los aspectos que más gustan y los que no del programa. La última pregunta - de carácter abierto- era por qué se mira Showmatch. El objetivo perseguido con la realización de la encuesta fue de tipo descriptivo, a los fines de caracterizar las maneras en que se consume el programa y los gustos de las audiencias. Con la información obtenida, se procedió luego a sistematizar las respuestas a partir de los aspectos que se reiteraban en las mismas. Las clasificamos, asignamos una serie de categorías centrales y obtuvimos los datos para el análisis ${ }^{3}$ a partir de los datos empíricos (Glaser y Strauss, 1967; Strauss y Corbin, 2002).

\section{SHOWMATCH, MUCHO MÁS QUE UN PROGRAMA}

El mapa de medios audiovisuales en Argentina está compuesto por medios de gestión privada, estatal y sin fines de lucro. La televisión de aire de alcance nacional se encuentra conformada por cinco canales, cuatro de ellos de gestión privada -Canal 13, Canal 9, Telefé y América- y Televisión Pública de gestión estatal. La televisión de aire se caracteriza por ofrecer una programación generalista que se organiza a partir de la competencia entre los canales (Di Guglielmo, 2010). Según los datos de la Encuesta Nacional de Consumos Culturales y Entorno Digital del año 20134, en Argentina el 97 \% de la población mira televisión, siendo el medio del sector audiovisual más elegido. Asimismo, en la última década se ha producido una migración de la audiencia hacia la televisión por cable, disminuyendo de manera sostenida entre 2006 y 2015 el consumo de la televisión de aire. En abril de 2016 el total del cable superó en audiencia a los canales de aire. La tendencia es hacia el crecimiento de la televisión on demand, siendo Netflix la empresa líder en servicio de streaming en América Latina. En el año 2011 fue su ingreso en Argentina y en abril de 2017 llegó a tener 847.458 suscriptores en el país. En segundo

\footnotetext{
2 Proyecto de investigación PICT 2015 «Televisión y crítica de medios en el contexto de la Ley de Servicios de Comunicación Audiovisual», integrado por Cecilia Toledo, Magalí Merchert y Carla Bleiz.

${ }^{3}$ El procesamiento de las respuestas se realizó a través del programa Atlas Ti.

${ }^{4}$ Realizada por el Sistema de Información Cultural de la Argentina (SInCA), dependiente del Ministerio de Cultura de la Nación.
} 
lugar se ubica Cine.arPlay con 477.944, luego Onvideo de Telefónica con 121.065 (Baladrón y Rivero, 2017).

Si bien año tras año la televisión de aire ve migrar a su audiencia hacia otras formas de consumo a partir de las múltiples pantallas, los servicios de televisión on demand y la hiperconectividad ${ }^{5}$, Bailando por un sueño se mantiene en la televisión de aire como el gran reorganizador del resto de la programación. Hugo Lewin (2015) plantea que Tinelli y su programa es el centro de gravedad del sistema televisivo, por la audiencia que concentra y por cómo el programa, en tanto discurso, entra en la circulación discursiva y en todo tema de conversación y referencia.

Los orígenes del programa se remontan al 1. ${ }^{\text {ero }}$ de marzo de 1990, bajo el nombre de VideoMatch ${ }^{6}$, se proponía ser un magazine deportivo en el horario de la medianoche y de una frecuencia diaria emitido en Telefé. En sus inicios el programa no pasaba de los 2 o 3 puntos de rating (Blua, 2011, p. 12), aunque con el paso del tiempo se posicionó entre los productos que más alto porcentaje de audiencia conlleva. Se mantuvo hasta el 2004 en Telefé, en 2005 pasó a Canal 9 y cambió el nombre por Showmatch, al año siguiente se transmitió por Canal 13, emisora en la que se mantiene hasta la actualidad. En el año 2006 se produjo un cambio en el formato, dejando a un lado las cámaras ocultas y comenzó el certamen Bailando por un sueño ${ }^{7}$, cuyo eje organizador es la competencia de diferentes ritmos de bailes de parejas conformadas por un «famoso» y un bailarín, siendo evaluados por un jurado integrado por personas vinculadas a la farándula y/o espectáculo. Cada pareja representa el sueño de una institución benéfica y a través de la evaluación del jurado y el voto de la audiencia es que las parejas de baile van pasando de ronda hasta lograr una ganadora.

Bailando por un sueño se ubica dentro del formato del reality show (García Fanlo, 2017). El programa interpela constantemente desde lo emotivo, se estructura en binomios dicotómicos en los cuales se organizan las peleas, discusiones y conflictos de los participantes y el jurado -hay buenos y malos, virtuosos y defectuosos, simpáticos y antipáticos-. Las peleas se generan, habitualmente, en las largas previas antes del inicio del baile y/o a partir de las devoluciones del jurado, siendo el maltrato y la burla un recurso habitual para iniciar una discusión. El programa se caracteriza por la interpelación de una solidaridad espectacularizada a partir del sueño a cumplir. La mediatización de lo político (Verón, 2001, Carlón 2016) es una constante, por ejemplo, los tres candidatos más votados para presidente en el 2015 participaron de la apertura, bailando e interactuando con sus imitadores; es frecuente la presencia de políticos en el estudio de grabación acompañando el baile de sus esposas/novias, así como también los políticos han actuado en el sketch de apertura en 2016 y 2017, entre otros casos. Showmatch también se caracteriza por una fuerte carga estigmatizadora y cosificadora hacia las mujeres, a quienes se las trata como objetos sexuales para ser exhibidos. También se utilizan las redes sociales (Twitter, Instagram) para subir fotos en directo y marcar temas de conversación. Otro protagonista del programa es la publicidad que se hace presente constantemente tanto en al interior del producto como en las tandas. Showmatch y su certamen de baile se caracterizan por la repetición, año tras año, en su estructura y contenido, aunque con leves discontinuidades según la coyuntura específica, se puede incorporar más la cuestión política, el uso de las redes sociales, etc. (García Fanlo, 2017). Coincidimos con Alabarces (2011), quien explica que: «el principio que ordena el show es la redundancia, todo sucede dos veces $-\mathrm{y}$ también tres. Nada pasa en el programa sin que Tinelli lo cuente antes a los gritos (...) Tinelli entiende que su público es idiota y le explica todo antes, por las dudas no se entienda» (p. 72).

Existen una gran cantidad de programas satélites que colaboran en la tematización constante de Showmatch. Las figuras secundarias de Showmatch son los protagonistas de estos programas que cubren

\footnotetext{
${ }^{5}$ Para mayor ampliación en torno a los debates sobre el futuro de la televisión o el fin de los medios masivos consultar Carlón (2016), Carlón y Scolari (2009), Pérez de Silva (2000), Pscitelli (1998), entre otros.

${ }^{6}$ Para más información consultar Mangone (1992).

${ }^{7}$ Programa que dio origen a otros certámenes dentro del mismo tipo: Cantando por un sueño, Patinando por un sueño, El musical de tus sueños, Bailando Kids y Soñando para bailar.
} 
la franja horaria de la tarde y los fines de semanas. Sirvén y Ulanovsky (2009) en su último libro sobre la televisión ofrecen los siguientes datos: «En 2008, los ciclos de Marcelo Tinelli fueron tema de conversación en otros programas durante 226 días de los 242 que el ciclo se mantuvo en exhibición (...) resultó nombrado en 1112 oportunidades, a razón de casi 5 ciclos diarios» (p. 295). Los autores ofrecen datos precisos sobre los programas que nombran a Tinelli, según género al que pertenecen. De archivo y chismes: Ponele la firma, Zapping, Top Ten, TVR, Éste es el show, Resumen de los medios, Intrusos del espectáculo, Los profesionales de siempre, CQC, Pablo y Pachu, Bendita TV, Secretos de colección, Duro de domar, Ran 15, Resumiendo, El último vuelo del día, Infama. Magazines y ciclos de interés general: Almorzando con Mirtha Legrand, Mañanas informales, Tardes informales, AM, Impacto Chiche, Mañaneras, La casa de América, Argentinos por su nombre. Programas de entretenimientos y ficción: Hoy puede ser, El muro infernal, La mamá del año, Bella y Bestia, Mujeres de nadie. También en los programas de actualidad y noticieros: La cornisa, Arriba Argentinos, Noticiero 13 y Telenoche.

El concepto de McTele trabajado por Sampedro (2002) resulta interesante para analizar el funcionamiento McDonalizado (Ritzer, 1996) de la televisión, siendo Showmatch un claro exponente de ello, «Se ha incorporado de pleno a la audiencia como fuentes de ingresos, innovando y comercializando su “participación”. Concursantes, familias, amigos, seguidores y votantes carecen de garantías contractuales y el feedback con las nuevas tecnologías se limita al interés industrial» (Sampedro, 2002, p. 3). Showmatch promueve la participación del público a partir de su voto y de esta manera pueden cumplir el sueño que representa la pareja de baile. Es decir, configura una escena «solidaria» espectacularizada, que presenta un interés en juego sublimado como desinterés (Boito, 2012).

Mencionábamos que una protagonista estructurarte del programa es la publicidad, ocupa una gran cantidad de espacio tanto al interior del producto como en las tandas. Realizamos un visionado del programa y analizamos la inserción publicitaria, tomamos como caso de análisis la emisión del martes 20 de junio de 2017. Ese día Bailando por un sueño comenzó a las 22:39 y finalizó a las 00:11. Las tandas publicitarias se realizaron de 23:50 a 23:57 y de 23:59 a 00:06. Durante la transmisión del programa se emitieron 10 publicidades entre el comienzo y la primera tanda. En el segundo bloque, de solo dos minutos, se mencionaron otras dos marcas, nuevamente se produjo otra tanda publicitaria y en el último bloque se nombró una marca.

La inserción de la publicidad al interior del programa generalmente se realiza antes y/o después del baile de algunas de las parejas, o antes del veredicto del jurado. También aparecen logos de diferentes marcas en tres columnas en la parte inferior de la pantalla. En la emisión del 20 de junio se mencionaron 43 marcas correspondientes a los siguientes rubros: alimentación (Dushi Sushi, Knorr, Saladix, Ensure Advance, Mostaza, Luchetti); bebidas (Speed, Branca, Bon Aqua, Toro Viejo, Estancia Mendoza, Ser); construcción (Polacrin, Sodimac); tienda (Easy, Falabella); cuidado personal (Pantene, Natura, Dove, Cicatricure); electrónica (Frávega, Drean Dish, Samsung); industria cultural (Película: Mamá se fue de viaje); medicamentos (Pulmosan, Vick; Pharmaron, Centrum, Dulcolax, Tafirol, Ibupirac); restaurante (McDonalds); ropa (Liguria); servicios (Personal, Emergencias SA, Dr. Fhurmann, Answer, Galeno, Fibertel, Santander Río, Movistar); turismo (Travel Rock). Los resultados son poco auspiciosos en términos de la contaminación publicitaria.

De la poca literatura que se ha publicado acerca de Showmatch, podemos ubicar dos posicionamientos que intentan explicar el éxito del mismo. Por un lado, aquellos que entienden al programa a partir de sus televidentes y del carisma del conductor: «Marcelo Tinelli supo darnos lo que pedimos, lo que necesitamos, entendió como nadie la quinta esencia del alma televisiva» (Fulco, 2007, p. 11), «[Tinelli] consigue hacerse popular con cualquier cosa que haga. Tiene ángel, un encanto natural que no se fabrica con una fórmula» (Notar, 2017, p. 47). Por el otro lado, aquellos autores (Mangone, 1992, 2010; Alabarces, 2011) que desde un posicionamiento crítico proponen comprender a la televisión y sus productos dentro de un entramado mayor, es decir encuadrar su funcionamiento dentro de la vida social y material. 
Hasta aquí hemos identificado algunos rasgos del programa inserto en una televisión de aire que día a día ve migrar su audiencia hacia otro tipo de pantallas y consumos. Showmatch es un claro exponente de la televisión, conjuga entretenimiento, publicidad, política, redes sociales, farándula, escenas de alto contenido sexual, peleas. Continúa siendo un programa organizador del resto de la programación, con un alto nivel de reiteración, fuerte carga publicitaria, de funcionamiento Mcdonalizado y solidaridad «espectacularizada».

\section{RESULTADOS}

Nos detenemos ahora en la indagación sobre los gustos y formas de consumo de Showmatch, para así ponerlos en relación con las características del programa. Partimos de entender que los dos objetivos se articulan en la trama argumental sostenida por una hipótesis: los elementos constitutivos y permanentes del programa (el baile, el sueño a cumplir, las peleas, la publicidad) no conllevan necesariamente a ser motivo de elección.

En primer lugar, compartimos una breve caracterización sobre los hábitos de consumo de los encuestados. La gran mayoría (un 90 \%) afirma ver el programa a través de la televisión y en directo, quedando relegado el otro $10 \%$ a diferentes tipos de pantallas (computadoras, celulares, tablets). Este dato es interesante, ya que desde el campo de los consumos culturales, una gran parte de las investigaciones -tanto empíricas como de reflexión teórica- se preguntan y reflexionan sobre las modificaciones, desplazamientos y continuidades en las maneras de ver televisión a partir del predominio de las nuevas tecnologías y las múltiples pantallas. Por ejemplo, Padilla et al. mencionan «la explosión de las TICs, la convergencia tecnológica y cultural derivada de las mismas, aunada a la creciente interactividad de las diversas pantallas, está posibilitando la creación de una nueva vertiente en la recepción y consumo de los medios» (2011, p. 242). Un término muy utilizado es el de prosumidores (Jacks, 2011), que hace referencia al doble rol de consumidor y productor. Sin embargo, en el análisis de caso que aquí nos compete, los resultados demuestran que predomina un tipo de consumo más tradicional, anclado en el directo televisivo (Carlón, 2009) a diferencia de las nuevas tendencias de consumo donde las múltiples pantallas son las protagonistas. Asimismo, cabe mencionar que el propio programa en un intento de aggiornarse a este clima de época implementó como estrategia en el año 2011 que la audiencia se convierta en el quinto jurado del certamen y a través de la página web del canal podían participar votando (Notar, 2017). Posteriormente, hacia fines del año 2014, se intentó incluir el uso de las redes sociales, específicamente Twitter, como el quinto jurado. La second screen (Martel, 2015, p. 295), es decir la segunda pantalla que los espectadores utilizan mientras miran televisión no dio los resultados esperados en el caso de la votación vía Twitter y se levantó la propuesta ${ }^{8}$. La reticencia a dichas innovaciones podemos relacionarla con los motivos, por parte de los encuestados, por los cuáles se ve Showmatch. Sobre este punto retomaremos más adelante.

Suelen ver el programa solos un $41 \%$, en familia un $32 \%$ y en pareja un $23 \%$. En cuanto a la frecuencia del visionado preponderan quienes lo miran algunas veces a la semana. Un $81 \%$ afirma no haber votado nunca a los participantes del certamen, dando cuenta ello también del escaso nivel de interacción con el programa.

Mencionábamos en el apartado anterior que Showmatch se impone en la pantalla, ya que existen una gran cantidad de programas satélites y de espectáculos que se ocupan diariamente de repetir escenas del mismo, entrevistar a los participantes, mostrar los ensayos, etc. Sin embargo, los encuestados afirman no seguir el programa por otros medios en un porcentaje del $46 \%$. De los restantes, un $25 \%$

\footnotetext{
${ }^{8}$ Se logró 50.000 tuits por votación lo que equivale a medio punto de rating televisivo (García Fanlo, 2017).
} 
dicen seguirlo por otros programas de televisión, y por último, en porcentajes menores, se menciona la utilización de las redes sociales como manera de saber lo que sucede en Showmatch. Estos datos están en sintonía con la cantidad de visualizaciones que suele tener el programa o los fragmentos del mismo en el canal de Youtube, que es relativamente bajo en proporción al nivel de audiencia y popularidad que tiene el certamen.

Ahora bien, ¿Por qué se mira Showmatch? ¿Qué aspectos del programa son los que más gustan y cuáles los que menos? Estas preguntas nos permiten conocer los gustos y elecciones del consumo y en consecuencia complejizar los supuestos sobre los motivos de elección.

A partir de la clasificación y sistematización de las respuestas observamos que los aspectos que más gustan del programa son: el baile (57\%); el entretenimiento (17\%); el humor (14\%); el jurado $(14 \%)$, la vestimenta $(13 \%)$, la producción (11\%), la música $(10 \%)$, nada $(10 \%)$, Tinelli $(9 \%)$. Resulta interesante que un $10 \%$ responde por la negativa y afirma que no le gusta nada. Las demás respuestas se ubican en diferentes aspectos estructurantes del programa vinculados prioritariamente con el baile como pivote y a partir de este se menciona la vestimenta, la música, la producción y el jurado. Otro de los aspectos está vinculado con el entretenimiento y, por ende, se hace alusión al humor y la figura del conductor. Resulta al menos llamativo que aspectos relacionados con el «sueño» a cumplir y/o la solidaridad que es uno de los ejes estructurantes del programa no aparecen mencionados por parte de los encuestados.

En cuanto a los aspectos que no gustan del programa se menciona: las peleas (56 \%); el machismo (31 \%), el jurado (17\%), el chusmerío (17\%), las previas (9\%). Todos estos aspectos también son estructurantes del programa, sin embargo hacen alusión a un posicionamiento moral y/o ideológico en torno a la representación de las mujeres y su cosificación, el nivel de violencia y agresión que se transmite. En el apartado anterior mencionábamos la contaminación publicitaria que hay en el programa, sin embargo en las encuestas este tema no es sugerido.

Ahora bien ¿Qué relación guardan los elementos constitutivos del programa con la elección de consumo? ¿Por qué se mira Showmatch? No desconocemos que, para un mejor y más completo análisis, las respuestas a dichos interrogantes deben enmarcarse en un entramado mayor donde se realizan las prácticas de consumo, hacemos referencia a las estructuras económicas, políticas y sociales en las que se desarrolla. Sin desconocer ello, creemos que este análisis de caso puntual puede aportar a complejizar las miradas en torno al lugar hegemónico que tiene el programa.

$\mathrm{Al}$ sistematizar las respuestas observamos que se reiteraban tres tipos de posicionamientos con respecto al consumo de Showmatch, a los fines analíticos los denominamos: «Consumo vergonzante», «Consumo desatento» y «Consumo gozoso». Grillo, Papalini y Benítez Largui (2016) explican que generalmente en las investigaciones sobre consumos culturales las delimitaciones conceptuales no suelen ser muy claras, esto se corresponde con que abarcan prácticas o conjuntos de prácticas diversas y con el cruce de disciplinas y enfoques. Si bien existe amplia literatura en torno al tema (Wortman, 2015; García Canclini, 1995; Saintout y Ferrante, 2006; Jacks, 2011; Duek, 2014; Orozco Gómez, 2002; Sunkel, 2002; Grimson y Varela, 1999; Focas 2017; Moguillansky y Aliano, 2017; entre muchos otros) y no es el objetivo de este trabajo detenernos en ello, consideramos importante realizar algunas aclaraciones conceptuales.

Diversos autores plantean la polisemia de sentido en torno al consumo y a la recepción, lo que acarrea que en muchas ocasiones se los use indistintamente (Jacks, 2011; Grillo, Papalini y Benítez Largui, 2016). En este sentido es interesante la propuesta de Checa Montúfar (2011) quien reflexiona sobre lo «insuficiente» del término recepción y se pregunta si no se debería pensar en términos de 
consumo9. En este sentido es importante señalar que, si bien pertenece a un mismo campo semántico existen matices entre consumo, recepción, apropiación y uso. El trabajo de Grillo, Papalini y Benítez Largui (2016), resulta interesante para comprender el consumo, la recepción, y la apropiación como momentos de un mismo proceso que los van incluyendo. En cuanto a consumo lo definen como: «la selección y disposición al contacto, al diálogo, o a la interacción, orientada por el entramado social más amplio, de jerarquías e identificaciones; en síntesis, el consumo se da en un marco de condiciones impuestas por la oferta y enmarcada por relaciones sociales de poder establecidas. Ya sea un momento aislado o la capa exterior que recubre otras más sustantivas, indica una práctica que si bien no es suficiente es necesaria para la recepción y apropiación» (p. 239). Por recepción «como escucha, lectura o el momento del "ver" en el cual se produce la apropiación» (p. 239). Y por apropiación «lo interpretado, lo escuchado o visto, que produce un plus que le da sentido a la recepción. La apropiación habilita recuperaciones diversas como pueden ser aplicaciones y usos» (p. 239). Estas delimitaciones conceptuales permiten comprender a los términos como «esferas que se incluyen» (p. 239). Por lo mencionado es que optamos por hablar en términos de consumo, ya que dicho concepto incluye a los demás. Es interesante observar cómo en algunas de las respuestas de los encuestados se evidencian matices que recorren dichos campos semánticos. Por la elección metodológica y las preguntas que guían a este trabajo, no nos detendremos específicamente en ello, aunque haremos referencia en los casos que así lo ameriten.

\subsection{CONSUMO VERGONZANTE}

Por «Consumo vergonzante» hacemos referencia a aquellas respuestas que tienen como común denominador el justificarse con respecto al porqué se mira Showmatch. Dentro de este eje preponderan dos tipos de respuestas: 1) otro lo sintoniza, 2) no hay otra opción.

Con respecto al primer eje: «otro lo sintoniza», se hace referencia a un tipo de consumo vinculado con la «cotidianidad hogareña» ${ }^{10}$. Los diferentes miembros de la familia deben negociar, ceder, elegir y adaptarse al programa de televisión que se sintoniza. A más de 20 años de la investigación sobre las audiencias realizado por David Morley (1992) resulta llamativo que, al menos en el caso analizado, continúe primando un consumo colectivo atravesado por la cuestión del poder (no así de género). En tiempos de múltiples pantallas y consumos segmentados, Showmatch «se ve en familia», no es un dato menor el horario en que se transmite el programa (22:30 aproximadamente), coincidiendo con el momento de la cena, lo cual conlleva a que el grupo familiar se reúna. Compartimos algunas respuestas que ilustran lo mencionado:

«Porque en mi familia lo ponen a la hora de cenar».

«Porque mi familia lo mira a la hora de cenar y, muchas veces, se generan menos discusiones viendo un programa así que uno de la realidad».

«Porque lo ve mi familia a veces, sino no lo veo».

«Porque lo mira mi familia».

\footnotetext{
${ }^{9}$ Ejemplifica su propuesta a partir del caso de los pescadores muria de Sri Lanka citado por Morley: «En este grupo, los aldeanos más ricos (...) -dice Morley- suelen adquirir aparatos de televisión que exhiben como piezas esenciales de su colección de 'significantes de riqueza', a pesar de que la falta de suministro eléctrico hace que estos aparatos sean por completo inútiles desde el punto de vista funcional. No obstante, los objetos 'significan' potentemente, como lo haría el que yo me comprara el último modelo de televisor japonés de pantalla plana, con independencia de que llegara a encenderlo alguna vez» (2011, p. 311).

${ }^{10}$ Para mayor ampliación sobre el tema ver Roger Silverstone y su libro Televisión y vida cotidiana (1994).
} 
«Porque mi mamá lo ve y acapara la TV».

«Porque a mi hija le gusta».

«Porque a mi esposa le gusta».

«Porque mi familia lo ve de vez en cuando».

Silverstone (2007) menciona que el espacio de la vida cotidiana es donde los sujetos pueden ser libres, pero donde también sus posibilidades son reprimidas y explotadas, es por ello que enfatiza en estudiar la relación de los medios de comunicación en el ámbito de la vida cotidiana. Como se desprende del caso analizado, se mira Showmatch por cuestiones intrínsecas al ámbito doméstico, un análisis etnográfico podría aportar más datos sobre las relaciones de poder que se configuran al interior del hogar.

Entonces, si el primer eje hace referencia a cuestiones vinculadas con la cotidianidad hogareña, el segundo «No hay otra opción» hace mención a cuestiones vinculadas con la televisión en general. El consumo de Showmatch es motivado por contraposición al resto de la programación, ya sea por rechazo a programas referenciales (Orza, 2002) como son los noticieros o por oposición a la programación en general. Parecería que ver Showmatch entra como la «última opción». Compartimos algunas de las respuestas.

«Porque no hay nada para ver».

«Porque no encuentro otra opción de programación».

«Porque no están dando nada interesante en la tele y es mi última opción».

«Porque no hay nada en la tele, pero es muy de vez en cuando».

«Porque no suele haber nada interesante en otros canales que le compiten».

«Porque no hay nada más entretenido para ver a esa hora».

«Porque la realidad de los noticieros agobia».

«Porque no hay nada».

«Cuando no hay nada más interesante para ver deje el canal, pero prefiero dormir a verlo».

Es interesante observar cómo bajo esta categoría preponderan las respuestas por la negativa. Existe cierta tensión entre la justificación y la vergüenza ante el consumo de Showmatch, para ello se menciona como pivote de esta elección algún miembro de la familia que lo sintoniza o por contraposición al resto de la programación. Es decir, los motivos por los cuales se mira el certamen se ubican por fuera de los elementos constitutivos del programa. Se evidencia una suerte de «consumo forzado» sin mayor correlato en términos de uso y apropiación.

\subsection{Consumo Desatento}

Con esta categoría hacemos referencia a un tipo de consumo donde prevalece la atención desatenta ante el programa. Como menciona Raymond Williams (1974), la televisión y la radio imponen una atención desatenta a partir del concepto de flujo: «casi todos hemos vivido la experiencia, muy difundida aunque a menudo admitida con pesar, de que nos cuesta apagar el televisor. Repetidamente descubrimos que, aun cuando lo encendemos con la intención de mirar un "programa" determinado, nos hemos quedado mirando el siguiente» (p. 124). Dentro de esta categoría prevalecen cuestiones 
vinculadas a cierta desatención con relación al mirar el programa. Ubicamos tres ejes que se reiteran: 1) por casualidad, 2) para estar acompañado, 3) está de fondo.

Los últimos dos hacen referencia a un tipo de consumo vinculado con la «cotidianidad hogareña». El «está de fondo» hace alusión, específicamente, al lugar que ocupa el televisor en la vida cotidiana, como un elemento permanente dentro del hogar, que está encendido y se lo ve mientras se realizan otras actividades. Compartimos algunos ejemplos:

«Lo miro muy cada tanto generalmente como sonido de fondo mientras hago otra cosa».

«Lo pongo de fondo mientras lavo los platos porque no tengo que prestarle atención».

«La tele está prendida y queda de fondo mientras ceno o hago alguna otra cosa».

«Para estar acompañado» también hace referencia cuestiones vinculadas con la cotidianidad hogareña en términos más de compañía. Algunos ejemplos son:

«Por poner algo a la hora de ir a dormir».

«Porque llegó de trabajar a esa hora».

«Veo el programa porque durante la cena todos los programas ya empezaron y para Showmatch no hay que tener una continuidad para ver y entender de qué se trata».

«Miro un show, un rato antes de dormin».

En cuanto al eje «por casualidad» hacemos alusión a cuestiones vinculadas con la lógica de la televisión, priman en estas respuestas el rapping como motivo por el cual se termina viendo el programa. Compartimos algunos ejemplos:

«Llego al programa al hacer zapping, no lo sintonizo directamente».

«Lo engancho haciendo zapping y me quedo. No lo veo casi nunca pero Tinelli me hace reír».

«Queda el canal prendido después de la novela».

«Suelo mirar ficción y luego está el programa, lo miro hasta que me duermo».

«Porque hago zapping y ahí caigo».

«No sé. Si prendo la TV y no voy especialmente a ver algo y lo cruzo haciendo zapping, lo veo».

Los tres ejes tienen en común cierta cuestión azarosa y/o indiferente ante el consumo de Showmatch, así como cierta caracterización del programa como fácil de seguir. También prevalecen aspectos vinculados con la «cotidianeidad hogareña» y «las lógicas de la televisión» como motivo de consumo del programa. Podemos observar tanto en este eje como en el anterior cierto distanciamiento para con el programa, se lo mira por razones ajenas al mismo y quizá por ello es la reticencia a la interactividad con las redes sociales, así como el predominio del visionado en directo. 


\subsection{CONSUMO GOZOSO}

Por «Consumo gozoso» hacemos referencia aquellas respuestas que manifiestan cierto placer y/o elección por la positiva del porqué se mira Showmatch. Ubicamos dos ejes que se reiteran: 1) ocio, 2) por el programa. La primera hace referencia a una elección dentro del tiempo libre disponible que conlleva distracción y diversión, tal como se manifiesta en las respuestas:

«Me entretiene, me divierte y me mantiene actualizado de los chismes de la farándula».

«Me divierte y desconecta de los cotidiano».

«Me divierte y me distiende».

«Porque me encanta ver bailar».

«Porque me entretiene, me gusta mirar los distintos bailes».

Por otro lado, se hacen presentes cuestiones intrínsecas al programa, tales como el baile, el conductor, las parejas.

«Porque me gusta la danza en general».

«Me gustan muchas parejas como bailan».

«Porque me gusta como presenta Marcelo Tinelli».

«Porque lo sigo desde que comenzó y me enganché siempre con los bailes, peleas y previas».

«Porque me gusta Pedro Alfonso y Laura Chávez y obviamente por Marcelo».

Por lo mencionado, ante la pregunta de por qué se mira Showmatch preponderan tres tipos de posicionamientos ante el consumo que lo explican y justifican. Asimismo, este se encuentra atravesado por las lógicas de la cotidianeidad hogareña -se lo consume porque otro miembro de la familia lo hace, o para estar acompañado mientras se realiza otra actividad-y por las lógicas de la propia televisión -porque se llega haciendo rapping, porque no se ofrece nada mejor-. Solo en las respuestas que manifiestan una abierta aceptación y elección del consumo por la positiva se observa que el programa en sí mismo es un componente y motivo de elección.

\section{CONCLUSIONES}

Showmatch y su certamen Bailando por un sueño se mantiene, casi inalterado, en la pantalla desde hace más de una década. Es un producto faro de la televisión de aire. Alrededor de él se organiza e ilumina el resto de la programación, se producen programas ad hoc y genera tema de agenda en los demás medios de comunicación. Partíamos de la hipótesis que los elementos constitutivos y permanentes del programa no conllevan necesariamente a ser motivo de elección por parte de las audiencias.

Prevalecieron en las respuestas tres tipos de posicionamiento ante el consumo de Showmatch, a ellos los denominamos: consumo vergonzante, desatento y gozoso. Asimismo, observamos que estos consumos se encontraban motivados mayoritariamente por cuestiones vinculadas a la cotidianidad hogareña y por aspectos intrínsecos de la propia lógica televisiva. Partimos de entender que, la televisión en general y sus programas en particular, se ubican dentro de un entramado mayor y, por ende, hay que encuadrar su funcionamiento y consumo dentro de la vida social y material, es decir las estructuras económicas, políticas y sociales en las que se desarrollan dichas prácticas. 
En el caso de Bailando por un sueño es interesante observar que prevalece un tipo de consumo desatento y vergonzante en uno de los programas más vistos y de mayor repercusión de la televisión argentina. En tiempos de múltiples pantallas, servicios de streaming on demand, intereses transitorios de consumo y personalización de la recepción, si nos guiamos por el análisis de caso aquí presentado parecería que con Showmatch prevalece lo contrario, un consumo más tradicional. Se lo mira por la pantalla del televisor, en la casa, muchas veces negociando esa elección con otro miembro de la familia y como forma de estar en compañía, se lo mira porque quedó encendida la televisión, se lo pone de fondo mientras se realiza alguna tarea hogareña, se llega a través del zapping, etc. Es decir, los elementos constitutivos y permanentes del programa no forman parte, prioritariamente, del motivo de elección.

Entonces, el recorrido aquí presentado nos ofrece un panorama interesante que nos permite continuar indagando en torno al consumo ampliando a otras preguntas de investigación ¿Qué tipo de interacción se realiza en las redes sociales en torno al programa? ¿Cómo convive un programa tradicional de la televisión de aire como Showmatch con la personalización de la recepción? ¿Por qué el uso de Twitter para votar no dio los resultados esperados? Estas preguntas son algunos ejes relevantes de las que futuras investigaciones podrían ocuparse para identificar las nuevas formas en que los espectadores conviven con las redes sociales y múltiples pantallas.

\section{BibLIOGRAFÍA}

Alabarces, P. (2011). Peronistas, populistas y plebeyos. Crónicas de cultura y politica. Buenos Aires: Prometeo.

Baladrón, M. y Rivero, E. (2017). La regulación de las plataformas OTT audiovisuales: un modelo para armar. Revista Fibra. Tecnologías de la Comunicación, 16.

Blua, B. (2011). El rating de la televisión. El numerito que mueve millones y desencadena pasiones. Ciudad Autónoma de Buenos Aires: La Crujía.

Boito, M. E. (2012). Solidaridad/es y Crueldad/es de clase. El «Orden Solidario» como mandato transclasista y la emergencia de las figuras de la crueldad. Buenos Aires: Estudios Sociológicos Editora.

Checa Montúfar, F. (2011). De la «recepción» al «consumo»: una necesaria reflexión conceptual. En N. Jacks (coord.), Análisis de recepción en América Latina: un recuento bistórico con perspectivas al futuro (pp. 13-17). Quito: Editorial «Quipus».

Carlón, C. y Scolari A. (2009). El fin de los medios masivos. El comienzo de un debate. Buenos Aires: La Crujía.

Duek, C. (2014). Consumos culturales en Argentina: tecnología, dispositivos y prácticas. En V. Papalini (coord.), Promesas y traiciones de la cultura masiva. Balance de 30 años de democracia en Argentina (pp. 155-179). La Plata: Editorial de la Universidad de La Plata (Edulp).

Duek, C. (2013). Infancias entre pantallas. Las nuevas tecnologias y los chicos. Buenos Aires: Capital Intelectual.

Duek, C. (2014). Juegos, juguetes y nuevas tecnologías. Buenos Aires: Capital Intelectual.

Carlón, M. (2016). Después del fin. Una perspectiva no antropocéntrica sobre la post-tv, el post-cine y y youtube. Ciudad Autónoma de Buenos Aires: La Crujía.

Encuesta Nacional de Consumos Culturales y Entorno Digitial. (2013). SInCA Sistema de Información Cultural de la Argentina Disponible en:

$<$ https://www.sinca.gob.ar/VerDocumento.aspx?IdCategoria=10 $>$.

Focas, B. (2017). Apropiaciones de los públicos en torno a las noticias de inseguridad. Revista Astrolabio, 19, 6-31.

Fulco, M. (2007). El otro lado de Bailando por un sueño: cómo se construye el mayor éxito de la televisión argentina. Buenos Aires: Sudamericana.

García Canclini, N. (1995). Consumidores y Ciudadanos. Conflictos multiculturales de la globalización. México: Grijalbo. 
García Fanlo, L. (2017). Bailando por un sueño: regularidades y discontinuidades en el umbral del siglo XXI. Ponencia presentada en XII Jornadas Nacionales de Sociología. Carrera de Sociología, Facultad de Ciencias Sociales, Universidad de Buenos Aires.

Glaser, B. y Strauss, A. (1967). The Discover of Grounded Theory: Strategies for Qualitative Research. Chicago: Aldine.

Grillo, M., Papalini, V. y Benítez Largui, S. (2016). Estudios sobre consumos culturales en la Argentina contemporánea. Ciudad Autónoma de Buenos Aires: CLACSO.

Grimson, A. y Varela, M. (1999). Audiencias, cultura y poder. Estudios sobre la televisión. Buenos Aires: Eudeba.

Heram, Y., Toledo, C., Merchert, M. y Bleiz, C. (2017). Tendencias actuales de los canales de aire de la televisión argentina. Ciencias Sociales, 94, 138 -141.

Jacks, N. (2011). Análisis de recepción en América Latina: un recuento histórico con perspectivas al futuro. Quito: Editorial «Quipus».

Landi, O., Vacchieri, A., Quevedo, L. A. (1990). Públicos y consumos culturales de Buenos Aires. Buenos Aires: Cedes.

Mangone, C. (1992). Tinelli. Un blooper provocado. Buenos Aires: La Marca.

Mangone, C. (2010). Tinellismo, veinte años son demasiado. Cuadernos Críticos de Comunicación y Cultura, 5.

Martel, F. (2015). Smart. Internt(s): la investigación. Buenos Aires: Taurus.

Moguillansky, M. y Aliano, N. (2017). De los consumos a las prácticas culturales. Una mirada desde las articulaciones biográficas. Revista Astrolabio, 19, 96-117.

Morley, D. (1992). Television, audiences and cultural studies. London - New York: Routhledge.

Mata, M. C. (1997). Públicos y Consumos Culturales en Córdoba. Córdoba: Centro de Estudios Avanzados, Universidad Nacional de Córdoba.

Notar, N. (2017). La televisión del futuro. Streaming, big data, on demand y el nuevo espectador. Ciudad Autónoma de Buenos Aires: Ariel.

Orozco Gómez, G. (1996). Televisión y audiencias. Un enfoque cualitativo. Madrid: Ediciones de la Torre.

Orozco Gómez, G. (2002). Recepción y mediaciones. Buenos Aires: Norma.

Orza, G. F. (2002). Programación televisiva. Buenos Aires: La Crujía.

Pérez de Silva, J. (2000). La nueva producción audiovisual en la era de Internet: La tercera revolución industrial. Barcelona: Gedisa.

Padilla, R., Repoll, J., González, D., Moreno, G., García, H., Franco, D., y Orozco, G. (2011). México: la investigación de la recepción y sus audiencias. Hallazgos recientes y perspectivas. En N. Jacks (coord.) (2011), Análisis de recepción en América Latina: un recuento histórico con perspectivas al futuro (pp. 227-268). Quito: Editorial «Quipus».

Piscitelli, A. (1998). Post/Televisión. Buenos Aires: Paidós.

Revista SociedadHD. (2015). Hugo Lewin y Ana Wortman reflexionan sobre Marcelo Tinelli, [Archivo de video]. Recuperado de < $\underline{\text { http://revistasociedadhd.sociales.uba.ar/tinelli-conduccion }>\text {. }}$

Ritzer, G. (1996). The McDonaldization of society. An investigation into the changing character of contemporary social life. California: Pine Forge Press.

Saintout, F. y Ferrante, N. (comps.). (2006). ¿Y la recepción? Balance crítico de los estudios sobre el público. Buenos Aires: La Crujía.

Sampedro, V. (2002). Telebasura: Mc'Tele y ETT. ZER. Revista de Estudios de Comunicación, 13, $29-44$.

Silverstone, R. (1994). Televisión y vida cotidiana. Buenos Aires: Amorrortu editores.

Silverstone, R. (2007). Media and morality on the rise of the mediapolis. Cambridge: Polity Press.

Sirvén, P. y Ulanovsky, C. (2009). iQué desastre la TV! [pero cómo me gusta...]. Buenos Aires: Emecé.

Strauss, A. y Corbin, J. (2002). Bases de la investigación cualitativa. Técnicas y procedimientos para desarrollar la teoría fundamentada. Bogotá: Contus, Universidad de Antioquía. 
Sunkel, G. (2002). Una mirada otra: la cultura desde el consumo. Buenos Aires: CLACSO, Consejo Latinoamericana de Ciencias Sociales.

Terrero, P. (1997). Ocio, prácticas y consumos culturales. Aproximación a su estudio en la sociedad mediatizada. Revista Diálogos, 49, FELAFACS, Lima, pp. 78-87.

Terrero, P. (1999). Ocio, prácticas y consumos culturales. Aproximación a su estudio en la sociedad mediatizada. En G. Sunkel (coord.), El consumo cultural en América Latina. Construcción teórica y líneas de investigación (pp. 196-213). Bogotá, Convenio Andrés Bello.

Verón, E. (2001). El cuerpo de las imágenes. Buenos Aires: Norma.

Williams, R. (2011 [1974]). Televisión. Tecnología y forma cultural. Buenos Aires: Paidós.

Wortman, A. (2015). Consumos culturales en Buenos Aires: una aproximación a procesos sociales contemporáneos. Buenos Aires: Universidad de Buenos Aires. 